\section{Technical Considerations}

The port placement and dissection is similar to that of a VATS lobectomy. The working incision should be placed over the major fissure on the basis of examination with either the thoracoscope or robotic scope. During the robotic portion of the procedure, the scope is placed in the working port. Modifications of port placement will be necessary depending on the patient's body habitus, the patient's lung anatomy, and the location of the tumor. A working port is recommended for control of the hilum and major vessels and is necessary to remove the specimen at the conclusion of the procedure.

\section{Comment}

The da Vinci Surgical System has several advantages over thoracoscopic surgery. The enhanced optics, which include 3-dimensional visualization and $12 \times$ magnification provide superior visualization than what is currently available in thoracoscopy. The surgical arms have distal endowrists, which simulate normal wrist movement, have scaled motion, and remove hand tremors. With the maneuverability of the endowrists and enhanced visualization, precise dissection of tissue and control of vessels is obtainable.
Robot-assisted lobectomy is a procedure that will continue to evolve. An understanding of robotic technology and VATS lobectomy are required to perform this procedure. This procedure requires a dedicated team approach, with a console and tableside surgeon. This case demonstrates the feasibility of performing an anatomic pulmonary resection with the da Vinci Surgical System.

\section{References}

1. Roviaro G, Rebuffat C, Varoli F, Vergani C, Mariani C, Mariocco M. Videoendoscopic pulmonary lobectomy for cancer. Surg Laparosc Endosc Percutan Tech. 1992;2:244-7.

2. Kirby TJ, Mack MJ, Landreneau RJ, Rice TW. Initial experience with video-assisted thoracoscopic lobectomy. Ann Thorac Surg. 1993;56: 1248-53.

3. McKenna RJ. Lobectomy by video-assisted thoracic surgery with mediastinal node sampling for lung cancer. J Thorac Cardiovasc Surg. 1994;107:879-82.

4. McKenna RJ, Wolf RK, Brenner M, Fischel RJ, Wurnig P. Is lobectomy by video-assisted thoracic surgery an adequate cancer operation? Ann Thorac Surg. 1998;66:1903-8.

5. Yim PC. VATS major pulmonary resection revisited-controversies, techniques, and results. Ann Thorac Surg. 2002;74:615-23.

\title{
Transcardiac gunshot wound recognized forty-eight years later
}

\author{
James B. McClurken, MD, ${ }^{a}$ William J. Hammer, MD, ${ }^{b}$ and Bradford J. Lin, MD, ${ }^{b}$ \\ Abington and Philadelphia, $\mathrm{Pa}$
}

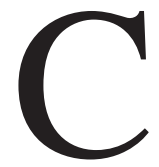

urrent treatment for transcardiac gunshot wounds (GSWs) includes expedient surgical repair. We performed coronary revascularization on a veteran of the Korean conflict who had been shot in the left axilla. The bullet was retrieved 2 days after the GSW through a superficial right chest wall incision, and the patient was told the missile "missed his heart by an inch." During the recent revascularization, plug-like calcific scars proved entrance at the lateral left atrium base of the appendage and exit at the right atrium midlateral wall. Thus this might represent the first reported survivor of a transcardiac GSW without direct repair.

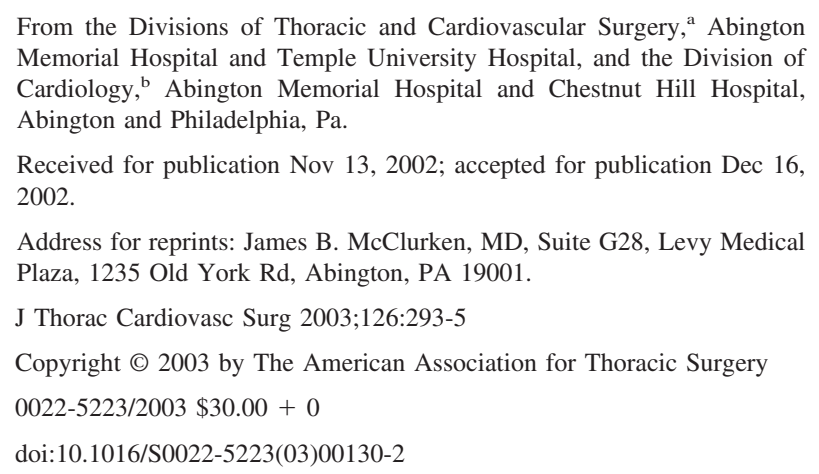

\section{Clinical Summary}

A 70-year-old hypertensive man had worsening stress test results. Catheterization revealed a $35 \%$ lesion of the left main coronary artery, a $90 \%$ blockage of the ostium of the left anterior descending artery (LAD), and a $60 \%$ mid-LAD blockage involving a large diagonal branch with multiple $30 \%$ to $40 \%$ lesions involving all other vessels. Echocardiography revealed left ventricular hypertrophy, mild mitral regurgitation, mild tricuspid regurgitation, and normal left ventricular function. Neither an atrial nor a ventricular septal defect was seen.

The history was significant for a GSW to the chest. The patient stated he was wearing a flak jacket while on patrol in June 1953, when he was hit 7 times by bullets to the torso. The flak jacket deflected 6 of the bullets, but a seventh entered the left axilla (Figure 1, A). Because of the hostile fire, a medic dressed the wound and informed the patient he would have to walk 3 miles to the nearest mobile army surgical hospital. On arrival, the patient collapsed into the tent. Resuscitation included 3 pints of blood; he described subcutaneous emphysema of the entire chest wall.

The patient was then transferred to Tokyo, where a US military surgical team performed a lateral thoracic incision (Figure 1, B) and removed the bullet from superficial tissue, stating the flak 

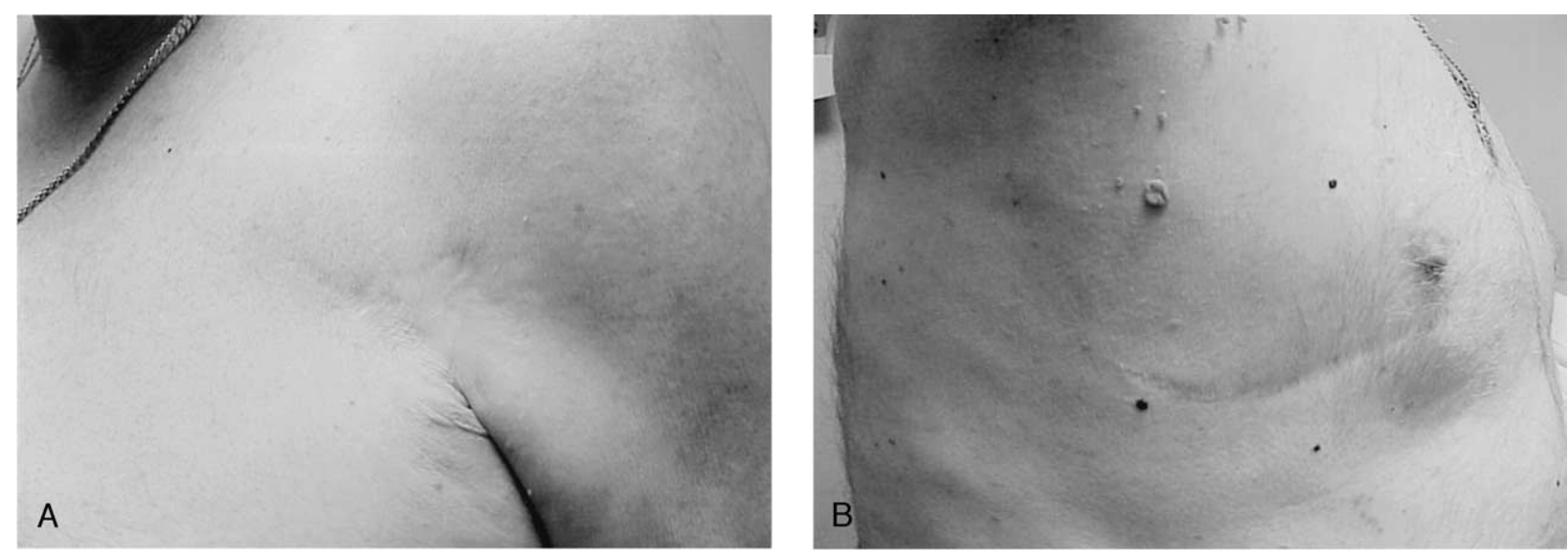

Figure 1. A, View of left axilla showing surgical scars. B, Right lateral chest wall.

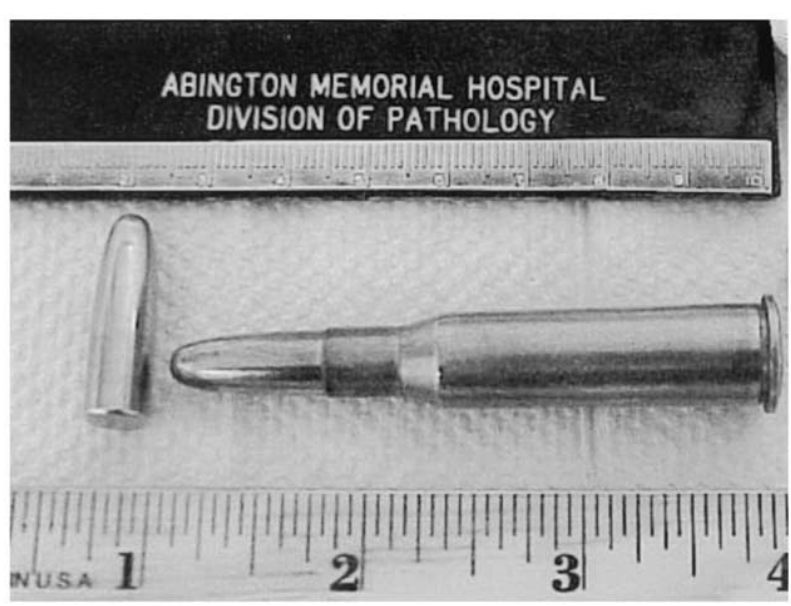

Figure 2. Bullet removed from left axilla in 1953.

jacket prevented the exit wound. He was given the bullet (Figure 2). Over the ensuing 3 days, he described daily thoracentesis for a pint of bloody fluid. He subsequently recovered.

With this history, preoperative computed tomographic scanning demonstrated calcific areas along the left lateral and right lateral pericardium; no foreign body was seen (Figure 3). The trajectory aligns with the left axillary and right lateral chest wall wounds. On November 17, 2001, the patient underwent coronary artery bypass grafting twice with the left internal thoracic artery grafted to the LAD and a saphenous vein graft to the diagonal artery. At pericardiotomy, generalized adhesions were encountered, as was a calcific plug-like reaction where the pericardium was fused to the base of the left atrial appendage, for a diameter of about $0.5 \mathrm{~cm}$. A similar finding was noted at the right atrial lateral wall with $1-\mathrm{cm}$ plugging. His recovery after coronary artery bypass grafting was uneventful.

\section{Discussion}

We postulate that the small-caliber (approximately 0.30) full-metal jacket military round did not deform, deflect, or tumble, and it caused small holes in low-pressure chambers. Tamponade and
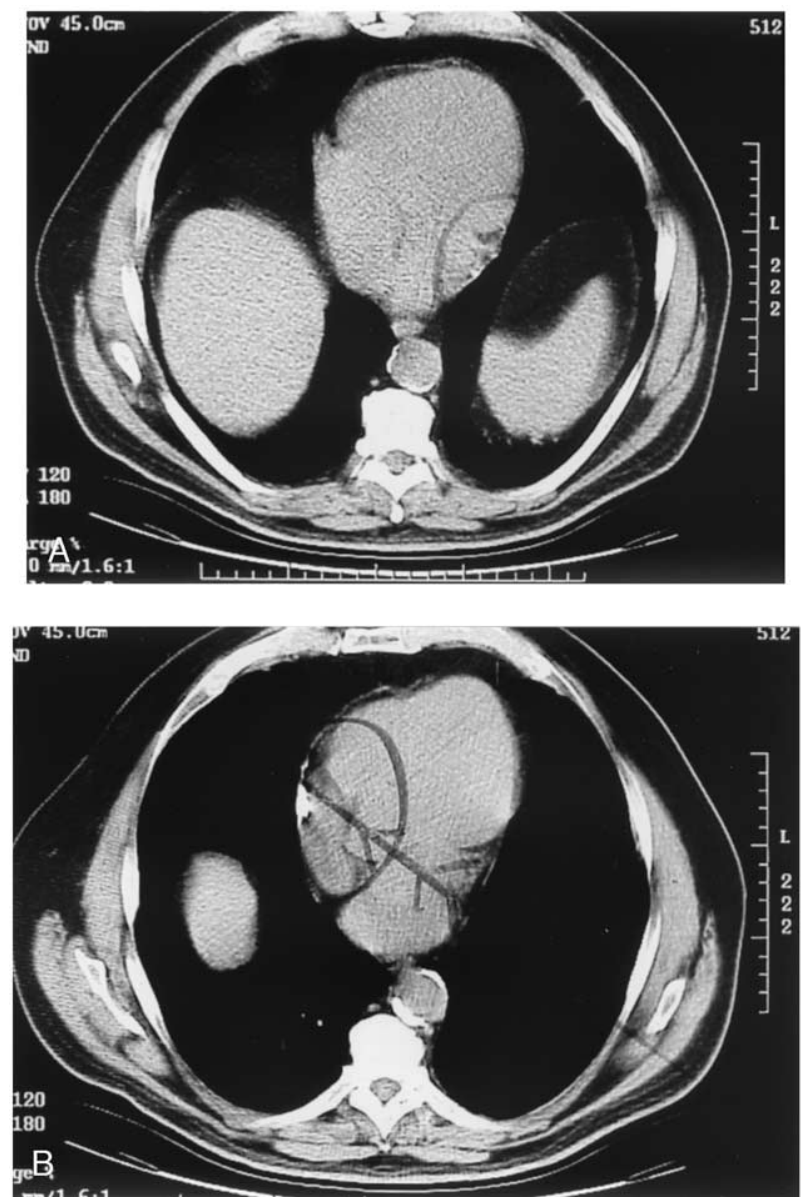

Figure 3. Computed tomographic scans.

hypotension ensued and was later treated with blood infusion. Delayed thoracentesis implies ongoing oozing from the pericardial-atrial holes. The bullet likely traversed the atrial septum obliquely, and the atrial septal defect appears to have healed.

A review of the literature ${ }^{1-4}$ fails to reveal any survivor of a transmediastinal GSW without prompt direct surgical repair. Al- 
though we are certainly not advocating conservative management of transmediastinal GSWs, survival might be possible (rarely).

\section{References}

1. Johnson SB, Nielsen JL, Sako EY, Calhoon JH, Trinkle JK, Miller OL. Penetrating intrapericardial wounds: clinical experience with a surgical protocol. Ann Thorac Surg. 1995;60:117-21.
2. Wall MJ Jr, Mattox KL, Chen CD, Baldwin JC. Acute management of complex cardiac injuries. J Trauma. 1997;42:905-12.

3. Moreno C, Moore EE, Majure JA, Hopeman AR. Pericardial tamponade: a critical determinant for survival following penetrating cardiac wounds. J Trauma. 1986;26:821-5.

4. Kulshrestha P, Das B, Iyer KS, Sampath KA, Sharma ML, Rao IM, et al. Cardiac injuries—a clinical and autopsy profile. J Trauma. 1990;30: 203-7.

\title{
Bilateral lung transplantation for pulmonary hypoplasia caused by congenital diaphragmatic hernia
}

\author{
Richard Lee, MD, Eric N. Mendeloff, MD, Charles Huddleston, MD, Stuart C. Sweet, MD, PhD, and \\ Maite de la Morena, MD, St Louis, Mo
}

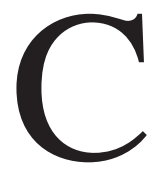

ongenital diaphragmatic hernia $(\mathrm{CDH})$ remains a lifethreatening neonatal anomaly. Patients who have $\mathrm{CDH}$ without pulmonary hypoplasia have an expected mortality that ranges from $10 \%$ to $25 \% .^{1}$ However, when pulmonary hypoplasia is associated with $\mathrm{CDH}$, the prognosis is even worse. Although the introduction and use of extracorporeal membrane oxygenation (ECMO) has improved survival in patients with unilateral pulmonary hypoplasia, mortality still ranges from $20 \%$ to $40 \%$ in this group. ${ }^{1} \mathrm{CDH}$ with bilateral pulmonary hypoplasia is a condition that has previously been incompatible with life.

Several innovative therapies have been offered in an attempt to improve the outcome in these high-risk patients. One of these therapies is lung transplantation. This option is often discussed as a potential solution and has some experimental support. ${ }^{2,3}$ However, the clinical experience in the literature is limited to a case report of a unilateral lung transplantation, ${ }^{4}$ followed by a transplant pneumonectomy nearly 5 years after transplantation. ${ }^{5}$ Here we present the outcomes of 3 patients in whom bilateral lung transplantation was performed for pulmonary hypoplasia associated with $\mathrm{CDH}$ at our institution.

\section{Clinical Summaries}

PATIENT 1. A diagnosis of $\mathrm{CDH}$ was established at 18 weeks' gestation in a female fetus. An ultrasound demonstrated the stom-

\footnotetext{
From the Division of Cardiothoracic Surgery and the Department of Pediatrics, Washington University, St Louis, Mo.

Received for publication Sept 7, 2002; accepted for publication Dec 2, 2002.

Address for reprints: Richard Lee, MD, Department of Thoracic and Cardiovascular Surgery, Cleveland Clinic Foundation, 9500 Euclid Ave, Desk F-24, Cleveland, OH 44195 (E-mail: leer2@ccf.org).

J Thorac Cardiovasc Surg 2003;126:295-7

Copyright (C) 2003 by The American Association for Thoracic Surgery $0022-5223 / 2003 \$ 30.00+0$

doi:10.1016/S0022-5223(03)00202-2
}

ach, bowel, and part of the left lobe of the liver in the left chest and the heart in the right chest. Displacement of the heart made evaluation difficult. Shortly after birth, the child was blue and without respiratory effort. Initial physical examination was notable for absent breath sounds on the left, as well as heart sounds on the right. She was immediately intubated. Chest radiography demonstrated viscera in the left chest. Echocardiography demonstrated double-inlet left ventricle, transposition of the great arteries, subaortic stenosis, coarctation of the aorta, a patent ductus arteriosus, and a patent foramen ovale with left-to-right flow.

The patient's condition was extremely difficult to stabilize. Four hours after birth, ECMO was started. Epoprostenol (prostaglandin $\mathrm{E}_{1}$ ) was infused to maintain patency of the ductus arteriosus. A discussion was held with the family, who agreed that combined heart-lung transplantation would offer the best chance for survival.

On day 19, she underwent combined heart-lung transplantation and repair of the $\mathrm{CDH}$. The left lung was extremely small and the right lung was erythematous and small. Circulatory arrest was used to perform the aortic arch reconstruction. The remainder of the heart-lung transplantation was achieved in standard fashion, and the patient was weaned from cardiopulmonary bypass. Because it appeared that the intrathoracic space was too small for the donor organs, only the skin was closed. The sternum and ribs were left unapproximated. The diaphragmatic hernia was repaired with a large patch. Because the abdomen could not accept all of the viscera, a silo was placed.

Four hours after arrival in the intensive care unit, an episode of electromechanical disassociation prompted 4 minutes of cardiopulmonary resuscitation. Re-exploration only revealed decreased contractility of the right ventricle. ECMO was restarted. The abdominal silo exploration was also unremarkable. On postoperative day 6, day 25 after birth, ECMO was weaned, and the patient was decannulated. The abdomen was closed on day 28. On day 38 , a peritoneal catheter was placed, and peritoneal dialysis was initiated to treat fluid overload that was unresponsive to diuretic therapy. However, this was only marginally successful. Therefore, she was placed on continuous venovenous hemofiltration on day 74. Heparin was infused to maintain activated clotting times of 180 